\title{
El Brexit y el futuro de Europa
}

Pedro Manuel Rodríguez Suárez

\section{RESUMEN}

Este artículo analiza las relaciones entre el Reino Unido y la Unión Europea (UE), desde la ardua incorporación británica en la entonces Comunidad Europea hasta el fenómeno del Brexit. En este orden de ideas, este ensayo posee tres objetivos cardinales. El primero, evalúa las variables que han estado presentes a través de la historia en relación con el histórico distanciamiento británico vis-á-vis el proceso de integración del viejo continente. El segundo, analiza desde una perspectiva histórica las administraciones de los ex primeros ministros británicos y sus intereses en relación con la membresía del Reino Unido en la UE. El tercer y último objetivo, crea un escenario hipotético inherente a las consecuencias que eventual- mente podrían presentarse para el Reino Unido y la uE en relación con el eventual fin de la membresía británica de la UE.

Palabras clave: Reino Unido, integración europea, Brexit, opinión pública y euroesceptisismo.

\section{Brexit and the future of Europe}

\begin{abstract}
This article analyses the relations between the United Kingdom and the European Union (EU), from the arduous British incorporation into the European Community to the phenomenon of Brexit. In this way, this article has three cardinal objectives. The first, to evaluate the variables that have been present throug-
\end{abstract}

* Licenciatura en relaciones internacionales por la Universidad Iberoamericana, Ciudad de México, especialidad en estudios europeos por el ITAM y doctorado en estudios de integración europea por la Universidad de Varsovia, Polonia. Profesor-investigador de la Benemérita Universidad Autónoma de Puebla, México. Autor y coordinador de los libros Hacia una nueva Europa (2008), América Latina: integración, cooperación internacionaly medio ambiente (2012), Hacia la regionalización mundial (2013), Las relaciones internacionales de la Unión Europea, vol. I (2015), La Unión Europea: Estados miembros, Rusia, Ucrania y temas selectos de la nueva Europa del Este (2018) y Hacia una nueva Europa II, (2017). Asimismo, es autor de un número considerable de artículos científicos publicados en revistas indexadas en América y Europa. Miembro del Sistema Nacional de Investigadores, nivel 2, Conacyt, México. Miembro del grupo de investigación: "Conflictos Socioestructurales y Reconfiguraciones Regionales", BUAP, México. Ha efectuado estancias de investigación posdoctoral en Polonia, Argentina, Chile, Uruguay y Colombia. [pedrosuarezbuap@yahoo.com.mx]; [https://orcid.org/0000-0002-6597-5509].

Recibido: 30 de mayo de 2019 / Modificado: 17 de mayo de 2019 / Aceptado: 19 de julio de 2019

Para citar este artículo:

Rodríguez Suárez, P. M. (2020). El Brexit y el futuro de Europa. OASIS, 31, pp. 147-166

Dor: https://doi.org/10.18601/16577558.n31.09 
hout the history of relations between the EU and the United Kingdom that had created the historical British isolationism vis-à-vis Europe's integration process. The second, to assess from a historical perspective the administrations of the former British prime ministers and their interests in regard to the position of the United Kingdom within the EU. The third and final objective seeks to create a hypothetical scenario inherent to the consequences that could possibly arise in relation to the end of British membership in the EU.

Key words: United Kingdom, European integration, Brexit, public opinion and Euroscepticism.

\section{INTRODUCCIÓN}

El Reino Unido es un Estado que está compuesto por cuatro entidades políticas constituyentes: Escocia, Gales, Inglaterra e Irlanda del Norte y forma la segunda economía más grande e importante de Europa, así como la cuarta del mundo, según el Fondo Monetario Internacional y el Banco Mundial. Las islas británicas ingresaron en la Unión Europea (UE) en 1973, antes de que entrara en vigor el Tratado de Maastricht en 1993. Cuando el Reino
Unido se incorporó a la entonces Comunidad Económica Europa (CEE) solicitó la cláusula de "exención" del TM, o la cláusula de option out, como es conocida en su terminología en inglés. La cláusula de exención fue utilizada por el Reino Unido y la República de Irlanda en aras de quedar excluidos del Acuerdo de Schengen ${ }^{1}$. Posteriormente, el Reino Unido y Dinamarca utilizaron la misma cláusula con la finalidad de quedar excluidos de la tercera fase de la Unión Económica y Monetaria. En otras palabras, de absorber al euro, como moneda única europea.

Como es bien conocido, el Reino Unido siempre ha sido considerado como el outsider de Europa, debido a su histórico distanciamiento en relación con el proceso de integración de Europa. Asimismo, ha mantenido durante prácticamente toda la historia de sus relaciones con la UE, una actitud bastante euroescéptica vis-á-vis la unificación de Europa, lo que le ha provocado serias fricciones con Alemania y Francia, que tradicionalmente han impulsado un proyecto de integración in situ de corte federal, así como supranacional. En este contexto, algunos especialistas como Stanislaw Parzymies (2013), han caracterizado la relación histórica del Reino Unido con la UE

1 El Acuerdo de Schengen fue firmado el 14 de junio de 1985. Los miembros fundadores de este acuerdo fueron: Alemania, Bélgica, Francia, Luxemburgo y los Países Bajos. Posteriormente se incorporó Italia en 1990, España y Portugal en 1991, Grecia en 1992, Austria en 1995, Finlandia y Suecia en 1996 y finalmente Dinamarca en 1996. En cuanto a los nuevos miembros de la ue de Europa del Este, la República Checa, Estonia, Letonia, Lituania, Hungría, Malta, Polonia, Eslovenia y Eslovaquia adoptaron el Acuerdo Schengen en el 2007. Cabe mencionar que Irlanda y el Reino Unido, participan solo en algunos aspectos de dicho acuerdo. Bulgaria, Chipre y Rumanía no forman parte del Acuerdo de Schengen, debido a que aún no están preparados para adaptarlo. Finalmente, el Acuerdo de Schengen tiene como objetivo la libre circulación de ciudadanos europeos y de toda aquella persona que haya ingresado al Espacio Schengen de manera legal. 
como "un matrimonio ficticio y sin grandes compromisos".

Las variables en relación con el aislamiento británico en torno al proceso de integración de Europa son varias. En primer lugar, la ubicación geográfica del Reino Unido que lo colocan "dentro" pero a la vez "fuera" de Europa continental. En segundo lugar, a diferencia de la gran mayoría de los países de Europa, el Reino Unido no sufrió a gran escala las consecuencias de las invasiones de Alemania durante la segunda guerra mundial. En este sentido, Londres no sintió la necesidad de reconciliar a las potencias "victoriosas" y "perdedoras" del viejo continente después de la segunda guerra mundial. En tercer lugar, el Reino Unido desde una visión histórica, siempre ha preferido su alianza trasatlántica con Estados Unidos y no con sus vecinos europeos. En cuarto lugar, la relación del Reino Unido con la UE siempre ha sido compleja desde sus inicios hasta el día de hoy. Por citar un ejemplo Francia vetó en dos ocasiones (1963 y 1967) las primeras solicitudes británicas de adhesión a la CEE, lo que hasta hoy genera una gran irritación en la opinión pública británica, así como los partidos políticos de extrema derecha. En quinto lugar, para el Reino Unido el Commonwealth ${ }^{2}$ continúa teniendo un gran peso, debido a que simboliza su legacía como Imperium Britanicum y, en sexto lugar, nunca estuvo de acuerdo con establecer una integración de tipo supranacional y mucho menos de corte federal.

Cabe hacer alusión a que cuando se creó la CEE el Reino Unido fue invitado a participar como miembro fundador, sin embargo, rechazó dicha propuesta por el carácter supranacional de la CEE y prefirió crear, en la década de 1960, la Asociación Europea de Libre Comercio (AELC) ${ }^{3}$, como contrapeso de la CEE.

Por otro lado, mientras Berlín y París han mantenido a través de la historia el liderazgo de la integración europea, el Reino Unido con frecuencia ha rechazado y hasta refutado dicha integración. Asimismo, cuestiona constantemente las instituciones supranacionales de la UE, así como a los tratados que se han establecido, cuyo objetivo, en la mayoría de los casos

2 La Comunidad Británica de Naciones o la British Commonwealth of Nations representa una evolución histórica de las relaciones de las ex colonias británicas con el Reino Unido, que se encuentran en América, África, Asia y Oceanía. La Commonwealth es una asociación libre compuesta por Estados soberanos que comparten valores y visiones similares, así como un pasado histórico común. Entre los ideales que comparten dichos Estados resaltan: el compromiso por la democracia, el respeto por los derechos humanos y el Estado de derecho, así como la cooperación en torno al desarrollo sustentable.

3 La AELC es una asociación de libre comercio compuesta actualmente por Suiza, Noruega y Liechtenstein. Cabe mencionar que este grupo de países no deseó integrarse a la uE y por lo tanto creó su propia organización. Su objetivo consiste en promover la estabilidad económica y el libre comercio entre todos sus miembros. Los miembros fundadores de la Aelc fueron: Austria, Dinamarca, Reino Unido, Noruega, Portugal, Suecia y Suiza. La Aelc fue establecida el 4 de enero de 1960 por la Convención de Estocolmo. En 1961 se incorporó Finlandia, en 1970 Islandia y en 1991 Liechtenstein. El Reino Unido abandonó la AELC en 1972. Ante el retiro del Reino Unido de la AELC, la mayoría de sus miembros hicieron lo mismo en aras de incorporarse en la CEE. 
ha sido incrementar el nivel de integración de la actual UE. Aunado a lo anterior, Londres siempre ha considerado que existen políticas que son "únicas" y "exclusivas" de los miembros de dicha organización y que por ningún motivo pueden ser revocadas o tomadas en consideración por las instituciones supranacionales de la UE.

Resulta importante subrayar que el rechazo británico hacia el modelo de integración supranacional que proponen algunos miembros de la UE, principalmente Alemania y Francia constituye actualmente una de las principales variables en relación con el fenómeno del Brexit (El Mundo, 2016). Aunado a lo anterior, Londres siempre ha concebido la integración del viejo continente desde una perspectiva muy diferente en comparación con los principales miembros de la Ue que abogan por una unificación de tipo federal, tales como, Alemania Francia, Bélgica, España y Luxemburgo. En suma, siempre prefirió una unificación económica que no fuese más allá de un libre comercio o de un mercado único europeo.

En los últimos años el nivel de complejidad en torno a las relaciones entre el Reino Unido y la ue ha llegado a su máximo nivel, asimismo el euroescepticismo británico ha crecido de manera alarmante, principalmente debido a las siguientes variables: a) desempleo, b) crisis de migración y refugiados políticos, c) poco crecimiento económico, d) pérdida de soberanía, f) contribuciones británicas hacia el presupuesto de la UE, y g) la política agraria común (PAC).

En relación con la migración ilegal o legal que ha llegado en los últimos años al Reino Unido, dicha migración se ha incrementado de manera alarmante y en la mayoría de los casos los migrantes provienen de África, Asia, así como de los nuevos miembros de la UE de Europa del Este, principalmente de Polonia, Rumanía y Bulgaria. Por citar un ejemplo se calcula que más de un millón de migrantes polacos residen actualmente en las islas británicas. Otros migrantes que han escogido al Reino Unido para mejorar sus condiciones de vida son originarios de algunas ex repúblicas que conformaban la uRss, tales como: Bielorrusia, Moldavia, Ucrania y la propia Rusia.

Ante lo expuesto, el ex primer ministro británico David Cameron impulsó durante su campaña política, convocar a un referéndum en aras de evaluar la continuidad de la membresía británica de la UE. Cabe mencionar que dicho referéndum tomó efecto el 23 de junio de 2016. Los resultados del referéndum sorprendieron a la opinión pública no solo europea, sino también mundial, debido a que la mayoría de los británicos votó por el fin de la membresía de las islas británicas en dicha organización.

Este ensayo posee tres objetivos cardinales. El primero, analiza el arduo proceso de integración del Reino Unido en la CEE. Asimismo, evalúa las variables que han generado el histórico distanciamiento británico vis-á-vis el proceso de integración del viejo continente. El segundo, analiza las administraciones británicas y sus intereses en relación con la posición del Reino Unido en la UE, y el tercer y último, presenta un escenario hipotético en relación con las eventuales consecuencias que podrían presentarse para el Reino Unido y la UE, inherentes al fin de la membresía británica de la UE. 


\section{METODOLOGÍA}

Este artículo se fundamenta en una investigación de tipo mixta. En este sentido, es descriptiva y explicativa. Es descriptiva porque describe las relaciones tan complejas que han existido a través de la historia entre el Reino Unido y la UE. Aunado a lo anterior, hace alusión a las variables que han propiciado el histórico rechazo británico hacia el proceso de integración de Europa. Por otro lado, esta investigación es de tipo explicativo porque explica las variables que han generado el aislamiento británico en la UE a través de la historia. Cabe mencionar que se utiliza en este artículo una investigación de tipo explicativa con el objetivo de exponer una serie de factores que afectan hoy en día a la sociedad británica que propicia el rechazo hacia la membresía de la UE, fenómeno que quedó evidenciado con el resultado del referéndum antes mencionado.

Este ensayo se divide en cuatro secciones. La primera se concentra en la compleja incorporación del Reino Unido en la CEE. La segunda, aborda las administraciones de los ex primeros ministros británicos y sus intereses en torno a la integración europea. La tercera presenta un marco hipotético en relación con las eventuales consecuencias que podrían presentarse para el Reino Unido y la UE, inherentes al fin de la membresía británica de dicha organización. Cabe hacer alusión a que en la cuarta y última parte, se exponen las conclusiones de este artículo.

\section{HIPÓTESIS}

La hipótesis que acompaña este artículo es descriptiva de valor. En este contexto, sus- tenta el planteamiento inherente a que en los últimos años la sociedad británica ha sido severamente afectada por diferentes variables, entre las que resaltan: el desempleo, la crisis de migración y refugiados políticos, el poco crecimiento económico, los efectos negativos de la globalización, así como por el terrorismo. Sin duda alguna, las variables mencionadas han tenido una fuerte connotación en relación con el apoyo de la opinión pública en torno a la membresía de la UE, debido a que, desde la perspectiva de la mayor parte de la opinión pública británica, Bruselas es la responsable de las problemáticas antes mencionadas.

\section{Marco teórico: teoría de los \\ complejos de seguridad}

Este artículo se sustenta en la teoría de los complejos de seguridad. Cabe mencionar que esta teoría es presentada en el libro: Regions and Powers: a guide to global security order (Buzan y Waever, 2013). La teoría de la seguridad compleja interpreta los problemas de seguridad que aparecieron en el escenario internacional, en particular en el viejo continente, al concluir el orden bipolar. Sin embargo, para efectos de esta investigación se utilizará la teoría mencionada para comprender la crisis de identidad que actualmente está presente en la sociedad británica que, al final, tuvo como consecuencia el fenómeno del Brexit.

Cabe decir que cuando el autor apunta a "crisis de identidad", hace alusión a que la sociedad británica ya no se identifica como miembro de un sistema en donde se comparten costos y beneficios mutuos. El término de costos posee varias aristas. En este sentido, 
hace alusión a las contribuciones británicas vis-à-vis con los fondos europeos y así como ceder políticas soberanas hacia las instituciones supranacionales de la UE. En términos de beneficios, la sociedad y los líderes políticos británicos consideran que los beneficios relativos a la membresía de la uE son relativamente "endebles", debido a las principales problemáticas que enfrenta Europa que, de una manera u otra, impactan en la sociedad británica, tales como: la crisis migratoria y de refugiados políticos, el desempleo, el terrorismo, el auge de los partidos políticos de ultraderecha, los ultranacionalismos, así como las crisis económicas que afrontan algunos miembros de la UE.

Barry Buzan y Ole Waever fundamentan su teoría desde la perspectiva del neorrealismo, el globalismo, el regionalismo, así como de la identidad colectiva. Para comprender algunas variables que generaron el Brexit, se considera en esta investigación la terminología "identidad colectiva”. Daniela Rodríguez (2017) define el concepto de identidad colectiva como: "un conjunto de rasgos o características sociales, culturares, etc... propios de una colectividad que la definen y la distinguen de otra”. Con base en este concepto se puede defender la idea de que el Reino Unido pocas veces compartió un sentido de pertenencia inherente al proceso de integración de Europa. Cabe hacer alusión a que este fenómeno se vio reflejado cuando rechazó participar como miembro fundador de la otrora CE y decidió crear en 1960 la Asociación Europea de Libre Comercio (AELC).

Por otro lado, el centro de estudio de la teoría de los complejos de seguridad, se concentra en los complejos de seguridad regional, que aparecen en la obra: People States and Fear: an agenda for international security in the post cold war era (Buzan, 2007, p. 17), así como en el libro: Security: a New Framework for Analysis (Buzan, Waever y de Wildem, 1997, pp. 23-24). Cabe hacer mención a que, en los complejos de seguridad, los actores comparten una identidad colectiva y se identifican como interdependientes, por lo tanto, se establece in situ una integración regional en aras de contrarrestar las amenazas que eventualmente pueden afectar la seguridad de dicha región. Una vez más se puede hacer alusión a que el Reino Unido no compartió con el resto de los miembros de la ue la visión referente a la "identidad colectiva”, por lo que refutó constantemente las políticas supranacionales de la UE.

En términos de seguridad, Barry Buzan y Ole Waever mantienen la convicción de que los actores que intervienen para propiciar la estabilidad política de Europa superan la concepción tradicionalista en torno a la "soberanía”. Por lo tanto, el Estado ya no es el único actor que participa en aras de fortalecer y prevenir la seguridad de Europa, así como su desarrollo económico. Como es conocido la integración de Europa es única en el contexto internacional, por lo tanto, su supranacionalidad está por encima de algunas de las políticas soberanas de sus miembros. En este orden de ideas, se puede aludir a que el Reino Unido, así como sus líderes políticos en pocas ocasiones compartieron la idea de ceder la soberanía de políticas cruciales hacia las instituciones supranacionales de la UE, en particular relativas a migración, controles fronterizos, políticas laborales, monetaria (euro), y la apertura de las fronteras. 
Finalmente, la teoría de los complejos de seguridad aborda la importancia de la opinión pública en aras de legitimar el fenómeno relativo a la integración regional. Desde esta perspectiva se puede mencionar que la opinión pública británica dejó de creer en los grandes beneficios que proporciona la membresía de la uE, lo que finalmente propició el fenómeno del Brexit.

\section{EL REINO UNIDO Y LA UE: UNA RELACIÓN POROSA A TRAVÉS DE LA HISTORIA}

Las relaciones entre el Reino Unido y la UE desde sus inicios hasta hoy han estado marcadas por su alto nivel de porosidad. Cuando se creó la CEE el Reino Unido fue invitado a participar por sus miembros fundadores: Alemania, Francia, Italia, Bélgica, Holanda y Luxemburgo para sumarse a la integración del viejo continente, después de las nefastas consecuencias que generaron la I y II guerras mundiales en las sociedades y en las economías europeas. Sin embargo, el Reino Unido declinó dicha invitación debido al modelo de integración que promovían Alemania y Francia que era de tipo federal y supranacional, por lo que, en la década de 1960, decidió crear la AELC.

Sin embargo, debido a los logros que iba cosechando la CEE en términos económicos, el Reino Unido decidió incorporarse a la CEE y abandonar la AELC. Sin embargo, sus dos primeras solicitudes de adhesión fueron vetadas por Francia. El primer veto francés tuvo efecto en 1963 y el segundo en 1967. Cabe mencionar que en aquellos años, el ex presidente francés Charles de Gaulle, consideró que el ingreso del Reino Unido en la CEE connotaría la "injerencia y el dominio estadounidense en los asuntos internos de Europa”, fenómeno que desde la perspectiva del general de Gaulle estaba ocurriendo en la Organización del Tratado del Atlántico Norte (Otán). En este contexto, el general Charles de Gaulle retiró a Francia del mando militar de la Otán en 1966 y no fue sino hasta el 2009 cuando el presidente Nicolás Sarkozy incorporó de nuevo a Francia en el mando militar de la Otán. Después de los intentos fallidos por ingresar en la CEE, fue finalmente el ex primer ministro Edward Heath quien, en 1972, logró incorporar a las islas británicas en la CEE.

Por otro lado, en un referéndum que se llevó a cabo en el Reino Unido en 1975 para evaluar el estado de satisfacción de la opinión pública británica en relación con la CEE, el 65\% de la opinión pública respaldó la membresía británica en la CEE. Sin embargo, durante las dos primeras décadas del siglo XXI, dicho respaldo ha caído de manera dramática. Según un barómetro elaborado por Opinión/observer el 20 de febrero de 2015, de llevarse a cabo un referéndum en el Reino Unido sobre la permanencia en la UE, solo una mayoría muy pequeña votaría a favor (51\%), mientras un $49 \%$ votaría en contra ${ }^{4}$. Asimismo, tan solo una minoría del 22\% expresó tener "cierta confianza" hacia las instituciones de la UE.

\footnotetext{
4 Para mayor información véase: Majority of electorate would vote for UK to leave eu in latest poll, en: http://www. theguardian.com/world/2015/feb/21/majority-electorate-vote-uk-leave-eu-poll.
} 
El apoyo de la opinión pública británica en torno a la uE difiere según la edad, la entidad política de origen, el nivel de estudios, así como de las condiciones socioculturales y socioeconómicas de los británicos. En este sentido, el mayor número de euroescépticos se encuentra en la gente mayor de 60 años, los desempleados, así como en las personas que han perdido sus empleos por la competencia que genera la integración económica europea. De manera contraria las personas jóvenes entre 18 y 24 años de edad son las que expresan un mayor apoyo hacia la ue. Asimismo, el mayor apoyo proviene de las personas con mayor nivel de educación, así como de los hombres de negocios y los universitarios (Ibarra, 2019).
Por otro lado, existen notorias diferencias entre las 4 entidades políticas que comprenden el Reino Unido. En este sentido, el apoyo mayoritario proviene de Irlanda del Norte y Escocia, mientras el mayor rechazo se encuentra en Inglaterra y Gales, tal y como se puede observar en la Gráfica 1.

Históricamente existen algunos partidos políticos en el Reino Unido que son más propensos hacia la integración europea, mientras que otros comúnmente la han rechazado y se distinguen por ser totalmente antieuropeos. Estos partidos políticos expresan con frecuencia que el Reino Unido ha perdido su soberanía e independencia ante las instituciones supranacionales de la UE. Sin lugar a dudas, los partidos

\section{Gráfica 1}

1. ¿Permanecer o salir de la UE? resultado del referéndum británico por regiones

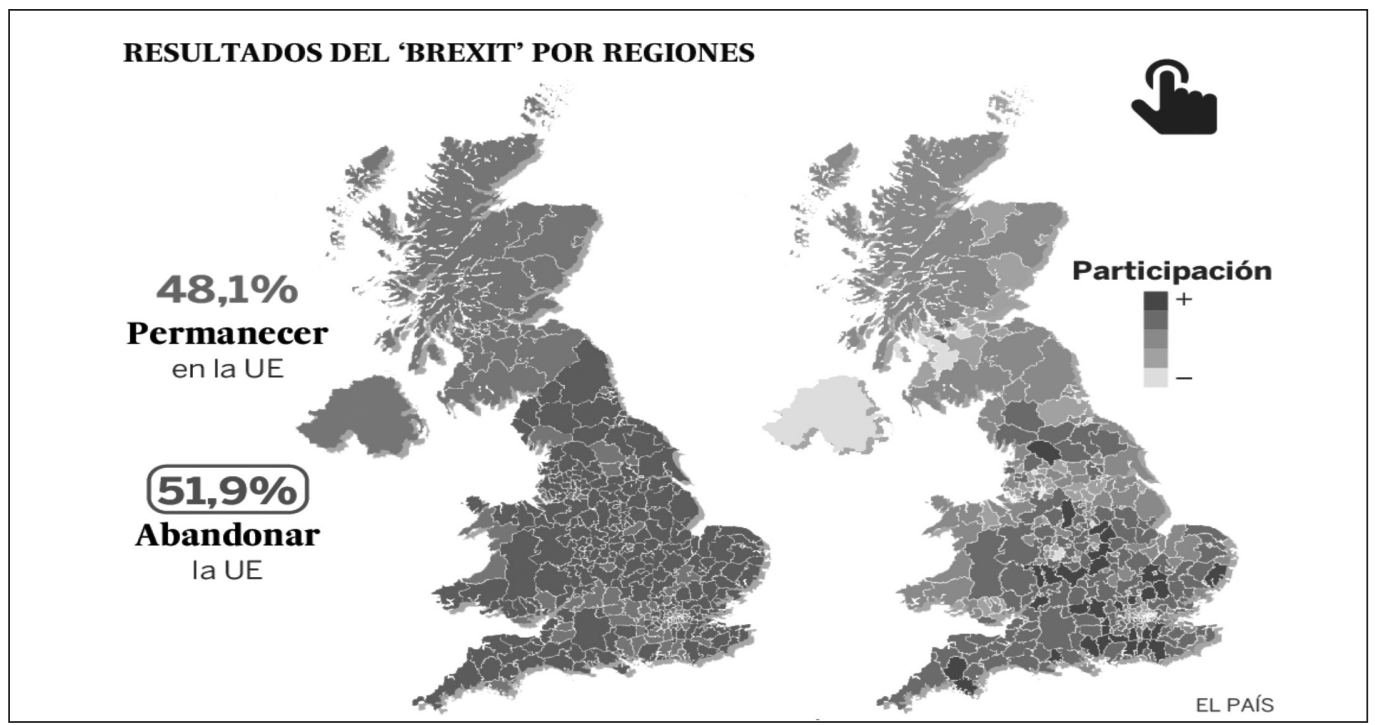

Fuente: El Pais, ‘Brexit’ vence y el Reino Unido dejará la Unión Europea, 24 de junio 2014. 
políticos más euroescépticos son el Partido de la Independencia del Reino Unido, el Partido Verde y el Partido Liberal Demócrata.

Por último, y no menos importante, estos partidos políticos son los que se han opuesto a la incorporación del Reino Unido a algunas políticas de integración que son fundamentales en el proceso de integración de la UE, tales como: la unión económica y monetaria, la libre circulación de personas, el euro, así como pertenecer al Acuerdo de Schengen.

\section{PRIMEROS MINISTROS BRITÁNICOS Y LA UNIÓN EUROPEA: ¿PROEUROPEÍSMO? O ¿EUROESCEPTICISMO?}

\section{Edward Heath: 1970-1974}

Sin duda alguna, Edward Heath fue uno de los ex primeros ministros británicos que más ha promovido la integración de Europa. Como se comentó con anterioridad, Edward Healh logró integrar al Reino Unido en la CEE en 1973. Su relación con la CEE no fue muy amplia debido a que se concentró en negociar la incorporación de las islas británicas en dicha organización. Desde su perspectiva solo una Europa fuertemente integrada podrá competir vis-à-vis con las economías desarrolladas y emergentes. Asimismo, desde su visión la integración de Europa es benéfica para todos los europeos debido a que permite el incremento de las inversiones, así como de la competitividad de las economías del continente.

Edward Heath siempre mantuvo una orientación proeuropea y se caracterizó por ser un gran enemigo de los regímenes totalitarios que existían en aquellos años en Europa del Es- te, así como de las dictaduras. Aunado a lo anterior era de la opinión de que la I y II guerras mundiales habían tenido como consecuencia la pérdida del liderazgo europeo en el escenario internacional, por la tanto, la integración de los países europeos era fundamental en aras de que Europa volviera a recuperar su liderazgo en la comunidad internacional.

En este sentido, en su obra The course of my life, apunta: "Europa se ha vuelto a marginar una vez más en su historia". "Mi generación tiene que trabajar para el futuro, solo trabajando juntos a lo largo y ancho de nuestro continente podemos tener alguna esperanza de llevar adelante los valores de la civilización europea". "Reconciliación y reconstrucción deben ser nuestras tareas prioritarias" (Heath, 1998 , p. 8).

\section{Harold Wilson: 1974-1976}

A diferencia de su predecesor Harold Wilson mantuvo una posición muy diferente vis-àvis con la CEE. Desde el punto de vista de los líderes europeos de su época, su actitud hacia la integración de Europa siempre fue "distante" y "obstruccionista", por lo tanto, solicitó que la membresía del Reino Unido fuese renegociada. Asimismo, abogó por reducir las contribuciones británicas del presupuesto de la CEE y de manera similar a lo que sucedió posteriormente con Margaret Thatcher, los socios comunitarios accedieron a dicha solicitud, con la finalidad de que el Reino Unido permaneciera dentro del proceso de integración del viejo continente. Cabe mencionar que Harold Wilson fue tan escéptico de la integración europea que convocó al primer referéndum para 
evaluar la permanencia del Reino Unido en la CEE en 1975. Como antes se mencionó, en esta primera ocasión el $67 \%$ de los británicos votó a favor, mientras una minoría de 33\%, manifestó estar en contra.

\section{James Challagan: 1976-1979}

La administración de James Challangan fue muy corta y en realidad tuvo que enfrentar problemas muy serios como el "invierno del descontento” (1978-1979). Durante estos años la economía británica se encontraba seriamente afectada. Más de un millón de personas se encontraban desempleadas, por lo que varios sindicatos convocaron a huelgas. Durante el proceso electoral en donde James Challagan buscó su relección fue derrotado por Margaret Thatcher, ante una opinión pública que se encontraba muy poco satisfecha con su administración. Otros problemas económicos con los que tuvo que lidiar fueron un déficit en la balanza de pagos y ataques especulativos hacia la libra esterlina. En términos de su visión de la integración europea, se le puede considerar como proeuropeo, pero no un líder activo que realmente promoviera la integración de Europa.

\section{Margaret Thatcher: 1979-1990}

Sin duda alguna, Margaret Thatcher representa un personaje muy polémico no solo en la sociedad británica, sino también en la opinión pública europea. Para algunos, la "dama de hierro" fue la "salvación" en relación con la crisis económica que enfrentó el Reino Unido durante la administración de James Challagan.
En adición, recuperó el prestigio internacional de las islas británicas como una gran potencia debido a que, de manera conjunta con otros líderes occidentales, logró derrocar a los sistemas totalitarios de Europa del Este y de la URss. Aunado a lo anterior, venció a Argentina durante la guerra que mantuvieron ambos países en 1982 por las islas Malvinas.

Sin embargo, otros segmentos de la opinión pública consideran que la "dama de hierro" fue un personaje muy severo en relación con los sindicatos británicos, Irlanda del Norte, así como, con el uso de la fuerza bélica en contra de Argentina, un país con menor desarrollo económico y tecnológico. De igual manera, esta parte de la opinión pública es del sentir de que las políticas neoliberales que trató de introducir Margaret Thatcher en el Reino Unido fueron catastróficas para la sociedad británica. En este sentido, el sistema neoliberal que trató de establecer Margaret Thatcher en la economía británica tuvo consecuencias catastróficas.

Desde el punto de vista del ex presidente del Parlamento europeo Martín Schulz, la frase que utilizó Margaret Thatcher durante la primera cumbre de la CEE en donde participó: "quiero que me devuelvan mi dinero", constituye hasta el día de hoy un acontecimiento histórico que ha marcado las relaciones entre el Reino Unido y la UE por décadas (Wallestein, 2015).

Cuando Margaret Thatcher llegó al poder en 1979 expresó su apoyo hacia la integración de Europa. Sin embargo, después solicitó el reembolso y la reducción de las contribuciones británicas hacia el presupuesto de la CEE, así como de la PAC. Tras arduas negociaciones 
y las enormes diferencias que se generaron, Thatcher recibió lo que posteriormente sería conocido como el "cheque británico".

En la mayoría de las ocasiones, Margaret Thatcher refutó y cuestionó la integración de Europa, así como su carácter supranacional. En este sentido, rechazó el establecimiento de una política exterior común de seguridad y defensa (PECSD), argumentando que el Reino Unido no estaría dispuesto a ceder parte de su soberanía y compartir políticas soberanas con las instituciones de la UE, en particular relativas a la PECSD, migración, controles fronterizos, monetaria, así como laboral.

Como es bien conocido, Margaret Thatcher siempre se opuso a la idea de una integración de carácter supranacional. Aunado a lo anterior rechazó que la burocracia europea tomara decisiones que desde su perspectiva solo les competen a los miembros de la CEE. Esta actitud hacia la CEE se puede evidenciar con sus declaraciones efectuadas en las reuniones de las CEE en donde participó de manera conjunta con otros líderes europeos: "parece que están en las nubes, si alguno de ustedes cree que iré al Parlamento y sugiera la abolición de la libra esterlina ¡no! ¡no! ¡no!... Hemos dejado muy claro que no se nos impondrá una moneda única europea”. En relación con las políticas supranacionales de la CEE mencionó: "Nuestra soberanía no proviene de Bruselas, es nuestra por derecho y por herencia" (Sanhermeland, 2016, p. 23).

Para algunos, Margaret Thatcher diseñó una política europea mejor conocida como "a la carta”. Es decir, se deslindó de todas aquellas políticas que no le interesaban, sobre todo, aquellas que consideró que son únicas de la soberanía británica. Paradójicamente fue su gran rechazo hacia la integración europea lo que en gran medida propició su dimisión en 1990, después de un discurso político que pronunció en Londres en contra de la integración de Europa, lo que luego la confrontó con su propio gobierno y con la opinión pública británica quienes, al final, apelaron por su dimisión.

Las relaciones entre el Reino Unido y la UE, durante la época de Margaret Thatcher, pueden caracterizarse como conflictivas, complejas y llenas de porosidad. En adición, siempre optó por establecer una asociación política y económica con Estados Unidos en vez de una alianza estratégica con los países del continente europeo. Margaret Thatcher es recordada en los ámbitos políticos europeos por sus habituales expresiones que con frecuencia aludían al "no, no a Europa".

\section{John Major: 1990-1997}

Durante la administración de John Major las relaciones entre el Reino Unido y la UE enfrentaron de nuevo serias fricciones. Dichas problemáticas tuvieron sus orígenes debido al incremento de euroescépticos en el Parlamento británico. John Major continúo utilizando la cláusula de "exención", en relación con la exclusión británica de acuerdos muy importantes. En este sentido, utilizó la cláusula antes mencionada en aras de eliminar cualquier posibilidad de integrar el Reino Unido a la tercera fase de la UEM que connota la adopción del euro como moneda única europea (Holmes, 1997). 
Aunado a lo anterior, los políticos conservadores de la época de John Major continuaron cuestionando la integración de Europa y las confrontaciones con la UE no cesaron. Finalmente, John Major retiró al Reino Unido de la legislación laboral europea, fenómeno que después sería revocado por el laborista Tony Blair en 1997. Cabe mencionar que la legislación laboral y social europea es el referente jurídico que establece el número de horas laborales que deben cumplir los empleados comunitarios, en términos de horas laboradas por día y por semana.

\section{Tony Blair: 1997-2007}

$\mathrm{El}$ arribo al poder del ex primer ministro británico Tony Blair connotó el fin de casi dos décadas de gobiernos "tories". Este acontecimiento significó un cambio radical en relación con la política exterior del Reino Unido hacia la UE. Tony Blair se mostró dispuesto a adoptar la legislación laboral europea. Sin embargo, rechazó incorporar al Reino Unido al euro y al Acuerdo de Schengen.

A pesar de lo citado, Tony Blair es un gran defensor de la integración europea. La posición proeuropea de Tony Blair se puede observar desde diferentes aristas, así como por sus declaraciones, efectuadas en los medios de comunicación internacionales en torno al Brexit. Al respecto, en una entrevista efectuada por el periódico alemán Der Spiegel, Tony Blair expresó: "si el Reino Unido abandona la UE, sería ignorar los grandes beneficios que las islas británicas han obtenido de la UE, como el desarrollo de la economía británica, que actualmente es la segunda más importante de
Europa y la cuarta más importante del mundo" (Fresneda, 2015).

Sin embargo, según el punto de vista de Tony Blair la uE necesita reformarse, debido a que la Europa del siglo xxI es muy diferente a la del siglo xx. Sumado a lo anterior, el viejo continente enfrenta una gran competencia del mundo desarrollado y emergente. Por citar un ejemplo, Tony Blair hace alusión al caso de China que se ha convertido en la segunda economía del mundo y que posee una población mucho mayor que la UE.

Desde la perspectiva de Tony Blair, el costo en relación con el fin de la membresía británica de la UE sería muy alto para las islas británicas, por lo que es de la opinión de que el Reino Unido debería permanecer en la UE y contribuir con las reformas que necesita efectuar la UE en aras de hacerla más competitiva y adaptarla a las realidades del siglo xxi (El Mundo, 2016).

Por otro lado, Tony Blair considera que la existencia de la UE en el siglo XXI no se justifica más por motivos de paz y por la reconciliación entre los países "victoriosos" y "perdedores" de la segunda guerra mundial, sino que la verdadera justificación del proceso de integración de Europa es la de convertir a la sociedad europea en la más competitiva del mundo. En este sentido, si el Reino Unido abandona la UE con seguridad será menos competitivo y perderá su influencia en la comunidad internacional, debido a que la uE connota un conglomerado conformado por 28 países europeos.

Por otro lado, Tony Blair ha expresado ante los medios de comunicación que la salida del Reino Unido de la ue, significará un "caos" y provocará una gran incertidumbre en 
el mercado laboral británico, así como la erosión de inversiones. Sin embargo, Tony Blair hace alusión a que existe un gran descontento en la opinión pública de las islas británicas en torno a la migración, los refugiados políticos, el desempleo, así como por las crisis económicas que se han presentado en algunos miembros del sur de Europa, tales como; Grecia, España, Italia y Portugal, por lo que el incremento del euroescepticismo británico en los últimos años ha sido alarmante (ídem).

\section{Gordon Brown: 2007-2010}

Las relaciones del Reino Unido con la UE durante la administración del ex primer ministro Gordon Brown regresaron a su notoria complejidad. Sin embargo, decidió ratificar el Tratado de Lisboa (TL) durante el 2008. No obstante, poco después de la ratificación del TL, Gordon Brown continuó expresando su gran euroescepticismo. Desde la perspectiva de Gordon Brown "existía la necesidad urgente de volver a negociar la membresía británica de la UE y recuperar las políticas soberanas".

De manera similar a sus predecesores, Gordon Brown rechazó adoptar el euro como moneda única europea. Asimismo, se opuso a la PAC, debido a que desde su perspectiva existen prioridades más importantes para Europa, tales como el desarrollo de la ciencia y la tecnología, la calidad de la educación, así como incrementar la competitividad de la infraestructura europea. Aunado a lo anterior, desde la visión de Gordon Brown la PAC lesiona a los consumidores, los agricultores, el medio ambiente, así como a las exportaciones de los socios del Reino Unido de la Commonwealth.
A pesar de lo dicho, Gordon Brown fue de la convicción de que el Reino Unido no debería retirarse de la UE, debido a que la pérdida de inversión extranjera sería incalculable (Brown, 2015).

\section{David Cameron: 2010-2016}

El ex primer ministro David Cameron, que representó la coalición política conformada entre el Partido Laborista y el Partido Liberal Demócrata, demostró durante su administración un profundo rechazo hacia la integración europea e inclusive prometió ante su electorado llevar a cabo un referéndum en torno a la continuidad de la membresía británica de la UE ( La Voz de Galicia, 2015).

Por otro lado, inmediatamente después de haber tomado el poder David Cameron enfrentó retos de suma importancia, como la eventual separación de Escocia, en el marco del referéndum que se llevó a cabo el 18 de septiembre de 2014. El movimiento político Yes Scotland (Sí Escocia) promovió la independencia de Escocia y la agrupación Better Together rechazó la independencia. Finalmente, como se puede apreciar en la Gráfica 2, el "no" por la independencia se impuso con el 55,3\% de los votos, frente al 44, 7\% de los partidarios por la independencia (Boix, 2012).

El euroescepticismo de David Cameron hacia la UE provocó fricciones con otros líderes europeos, empero también en el interior del Reino Unido, en particular con el Partido Escocés, que siempre se ha manifestado por continuar en la UE. Asimismo, David Cameron no logró transformar la histórica política británica de distanciamiento de la UE, por lo tanto, 


\section{Gráfica 2}

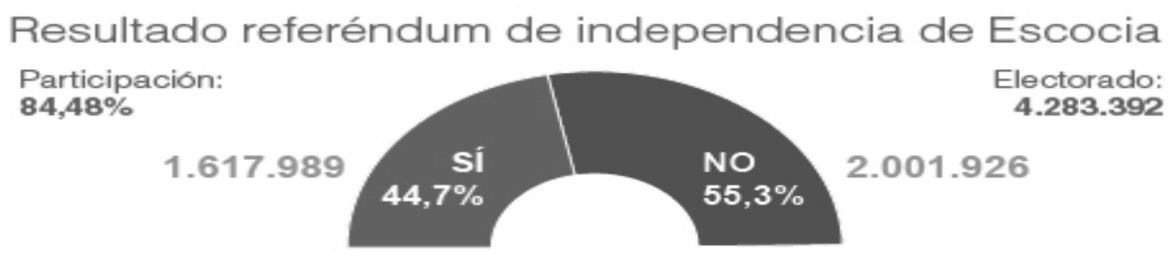

Encuestas intención de voto sobre la independencia escocesa

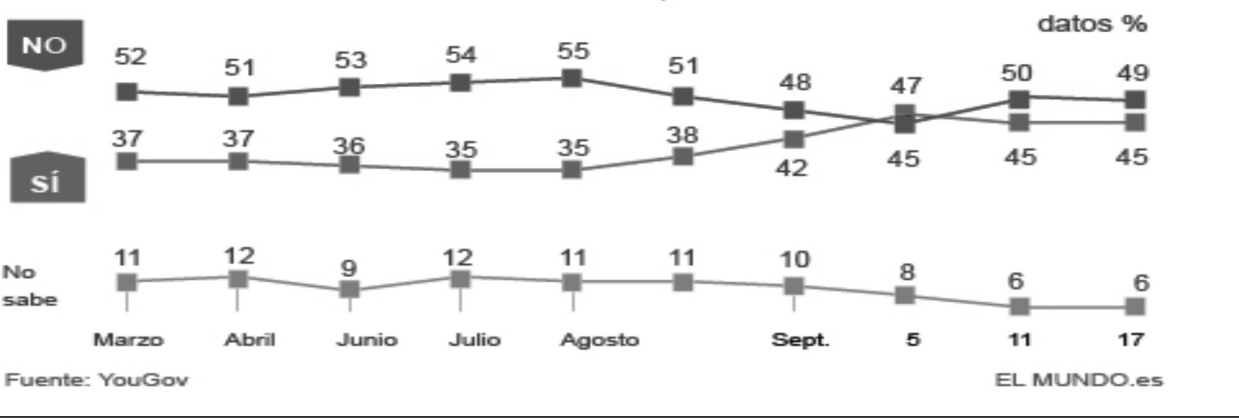

Fuente: El Mundo, 2014.

Londres continuó en la periferia de Europa. El gran aislamiento que mantuvo el Reino Unido de la ue durante la administración de David Cameron, se puede observar en su endeble participación en la guerra étnica de Ucrania, que tuvo efecto durante el 2015. Cabe destacar que Ángela Merker y François Hollande, fueron los únicos portavoces de la UE frente a la anexión rusa de Crimea, mientras el Reino Unido se caracterizó por su endeble participación.

En cuanto a las relaciones con la UE, David Cameron, de manera similar a Margaret Thatcher, deseó obtener más concesiones de la UE en particular en relación con el fortalecimiento del poder de los parlamentos europeos. Sin embargo, lo que realmente buscaba David
Cameron era utilizar la cláusula de "exención", con la finalidad de retirar al Reino Unido de la ley laboral y social europea, tal y como ocurrió durante la administración del ex primer ministro John Major.

En cuanto al referéndum, según algunos sondeos de opinión pública que fueron elaborados por algunos medios de comunicación, como The Telegraph, durante el 2015, se creía que el voto a favor de continuar dentro de la UE ganaría por una pequeña minoría. Sin embargo, dichos sondeos resultaron erróneos, tal y como lo demostró el resultado del referéndum convocado por David Cameron en el 2016 (Lilico, 2015). 


\section{Theresa May: 2016-2019}

Fue la segunda mujer del Reino Unido en ocupar el cargo de primera ministra. Su administración se caracterizó por concentrarse en tres puntos cardinales: a) la lucha en contra de la migración, b) el combate al terrorismo y c) la salida del Reino Unido de la UE. Asumió el cargo de primera ministra el 13 de julio de 2016, después de la dimisión de David Cameron, quien dimitió a su cargo después de los catastróficos resultados del referéndum en torno al Brexit.

Durante su primer discurso como primera ministra declaró: "a la vez que abandonamos la UE, forjaremos nuestro nuevo papel en el mundo. Valiente y positivo. Haremos del Reino Unido un país que funcione, no solo para unos pocos privilegiados, sino para todos los británicos" (El País, 2019). En relación con el Brexit, su frase más utilizada ante los medios de comunicación fue "Brexit means Brexit" (Brexit significa Brexit).

Según algunos especialistas su mayor error fue el de establecer un Consejo de Ministros que estuvo compuesto por políticos partidarios del Brexit y por aquellos que favorecen la permanencia del Reino Unido en la UE. El objetivo de Theresa May era el de crear consensos en torno a la negociación del Brexit con la UE. Sin embargo, dicho Consejo empeoró aún más las cosas y todo se convirtió en un caos. Un segundo error de Theresa May fue el de convocar a elecciones generales en el 2017. En el contexto de dichas elecciones Theresa May consideró que las urnas le darían el suficiente poder para impulsar el "Brexit duro". Sin embargo, el Partido Conservador perdió la mayoría absoluta y empezaron a depender de los socios norirlandeses del Dup. Finalmente, su tercer error fue el de tratar de mantener un consenso con uno de los personajes más euroescépticos del Reino Unido: Jeremy Corbyn.

La administración de Theresa May estuvo marcada por sus intentos fallidos para conseguir un acuerdo en torno al Brexit. En este sentido, presentó 3 veces sus propuestas ante el Parlamento Británico, y todas ellas fueron duramente criticadas y rechazadas.

Las negociaciones que comenzó a establecer con Bruselas han sido muy arduas, por lo que el presidente del Consejo Europeo, Donald Tusk, declaró ante los medios de comunicación: "hay un lugar especial en el infierno para aquellos que promovieron el Brexit sin tener siquiera un boceto del plan" (Ibid.).

Durante el inicio de las negociaciones Theresa May puso ante la mesa de negociaciones varias condiciones que forman parte de un "Brexit duro". En este contexto, propuso renunciar a la Unión Aduanera y establecer un acuerdo de libre comercio "lo más amplio y profundo posible”. Durante las negociaciones con Bruselas declaró: "no estamos dispuestos a aceptar las obligaciones de Noruega y al mismo tiempo tener los derechos de Canadá” (Ayuso, 2019). Posteriormente, Theresa May idealizó una tercera vía sobre el Brexit, en la cual "suavizaba" las cláusulas del acuerdo, con la intención de llegar a un compromiso sobre la futura relación aduanera con la UE.

Durante la última parte de su administración decidió abrir la posibilidad para permanecer dentro de la UE mediante un segundo referéndum, o bien, salir de la UE, pero continuar dentro de la Unión Aduanera. Sin embargo, 
fue duramente criticada por su propio partido político y prácticamente se quedó sola ante el inmenso reto que connotan las negociones en torno al Brexit. Ante este escenario tan caótico decidió dimitir como primera ministra británica.

\section{BREXIT}

A través de la historia de las relaciones entre el Reino Unido y la ue, la opinión pública y los líderes políticos del Reino Unido siempre se han cuestionado la membresía de la UE. Durante el 2015 el Parlamento Británico autorizó llevar a cabo un referéndum en torno a la membresía de la UE. Cabe mencionar que el referéndum que se llevó a cabo el 23 de junio de 2016, fue el segundo sondeo de opinión pública que se ha llevado a cabo para evaluar la permanencia del Reino Unido en la UE.

En el contexto del segundo referéndum la mayoría de los medios de comunicación, así como los estudios de opinión pública, estimaron que en esta ocasión los proeuropeos ganarían por un pequeño porcentaje. Sin embargo, los resultados del referéndum demostraron todo lo contrario.

Los partidos políticos y la opinión pública que votaron en contra manifestaron que habían votado de esa manera debido a la pérdida de soberanía, la crisis de migración y refugiados políticos, el desempleo, las crisis económicas que se habían presentado en algunos miembros de la ue del Sur de Europa, el terrorismo, así como por las contribuciones británicas al presupuesto de la UE. Asimismo, expresaron que debido al Brexit el Reino Unido recuperará su independencia, así como sus controles fronterizos.
Los partidos políticos y la opinión pública proeuropea aludieron que votaron a favor de permanecer en la UE, debido a que la membresía de dicha organización ha favorecido al desarrollo de la economía británica y que los beneficios de estar en la UE son mayores que la pérdida de alguna parte de la soberanía. Asimismo, esta parte de la opinión pública británica considera que las consecuencias en torno al Brexit serán muy altas debido a que se incrementarán las barreras comerciales para las exportaciones e importaciones británicas del mercado único europeo.

Existe una cantidad muy considerable de estudios que se han elaborado en torno a las eventuales consecuencias del Brexit, para el Reino Unido como para la UE. En este sentido, se prevén los siguientes escenarios:

\section{Reino Unido}

- Inestabilidad política debido a eventuales confrontaciones entre grupos políticos proeuropeos y antieuropeos.

- Se calcula que el Reino Unido tendrá que pagar 39 billones de libras esterlinas a la UE, por los compromisos adquiridos previos al fenómeno del Brexit.

- Considerables pérdidas económicas en la economía británica inherentes a la caída de inversiones comunitarias.

- Escocia, Gibraltar o Irlanda del Norte podrían independizarse del Reino Unido, debido a su interés por continuar dentro de la UE. Cabe resaltar que estas entidades políticas del Reino Unido han expresado que, debido al fin de la membresía del Reino Unido de la UE, podrían convocar 
a nuevos referéndum en aras de evaluar su pertenencia en el Reino Unido.

- La City de Londres perderá su estatus como el centro financiero de Europa, y París y Berlín podrían convertirse en las nuevas capitales financieras del viejo continente.

- Se prevé una fuerte disminución de inversiones en la industria financiera y automotriz.

- $\quad$ El Reino Unido puede perder el 5\% de su PIB debido a que la economía británica sufrirá la pérdida de empleos y de inversiones.

- En términos de comercio exterior las consecuencias podrían ser catastróficas, debido a que el $44 \%$ de las exportaciones británicas se dirigen hacia el mercado único europeo.

- El Reino Unido perderá su capacidad de negociación vis-à-vis terceros países en el escenario internacional, debido a que la UE representa un conglomerado de 28 países.

- Los ciudadanos británicos perderán su derecho a vivir, trabajar y jubilarse en cualquier país miembro de la UE.

\section{Unión Europea}

- El poder de negociación de la UE podría caer drásticamente en el escenario internacional debido al peso del Reino Unido en la economía y en la política internacional.

- El euroescepticismo británico podría contagiar a otros miembros de la Unión que eventualmente podrían seguir los pasos del Reino Unido y activar el artículo 50 del Tratado de Lisboa con la finalidad de concluir con su membresía de la UE.

- Los Fondos Estructurales y los Fondos de Cohesión se verían debilitados debido al fin de las contribuciones británicas. Cabe mencionar que el Reino Unido es considerado como un contribuidor "neto" para el presupuesto de la UE. En pocas palabras proporciona más recursos de los que recibe.

- En términos de política y seguridad internacional, también habrá serias consecuencias para la ue debido a que el Reino Unido posee la mayor capacidad bélica de Europa Occidental y es miembro permanente del Consejo de Seguridad de las Naciones Unidas.

\section{CONCLUSIONES}

Sin lugar a dudas, el Brexit ha creado una de las peores crisis que ha enfrentado la uE en toda su historia. Por primera vez un miembro de la UE ha decidido poner fin a su membresía en una organización que simboliza uno de los mayores logros en términos de integración en Europa y muy probablemente en la comunidad internacional. El 23 de junio de 2016, el 52\% de los británicos votó en contra de la membresía británica de la ue y el 48\% a favor. En realidad, pocos fueron los sondeos de opinión pública que acertaron con los caóticos resultados de dicho referéndum, a pesar de que en los últimos años el euroescepticismo había crecido de manera alarmante en el Reino Unido.

Las razones por las cuales la mayoría de la opinión pública británica votó en contra de continuar en la uE fueron varias, entre las que 
resaltan: recuperar los controles fronterizos, el terrorismo, la migración, el desempleo, los refugiados políticos, el sentimiento histórico británico en relación con la pérdida de soberanía, la PAC, así como dejar de contribuir con el presupuesto de la UE.

Los sectores de la opinión pública británica que se muestran a favor de la UE consideran que la integración europea ha contribuido a mantener la paz, la estabilidad y la prosperidad de Europa, así como con el crecimiento económico del Reino Unido después de la segunda guerra mundial, que lo ha convertido en la cuarta economía más importante del mundo y la segunda de Europa. Aunado a lo anterior, para esta parte de la opinión pública, debido al Brexit el Reino Unido perderá liderazgo $\mathrm{y}$ prestigio en las relaciones internacionales. Asimismo, las consecuencias económicas serán catastróficas en particular en relación con la erosión de inversiones y la City de Londres será sustituida por París o Berlín como centro financiero de Europa.

A pesar de las consecuencias tan negativas que generará el fin de la membresía británica para el Reino Unido, Theresa May y el Parlamento Británico invocaron el artículo 50 del TL, cuyo objetivo es finalizar con la membresía de la UE.

El fenómeno del Brexit ha puesto a reflexionar a los políticos europeos en torno al futuro de la UE. Para algunos, la UE debe regresar a su "corazón duro" de sus seis miembros fundadores, para otros la integración europea debe limitarse a un área de libre comercio y para otros hoy más que nunca la UE necesita reformarse y encontrar una nueva fórmula de integración, que responda a las necesidades actuales que enfrentan las sociedades europeas.

Hasta hoy no se sabe cómo concluirá la membresía del Reino Unido a la UE. Ante este escenario existen 4 posibilidades fundamentales. El primero, es que el Reino Unido vuelva a incorporarse en la AELC. El segundo, es que se establezca una asociación muy cercana y privilegiada entre el Reino Unido y la ue (tal y como es el caso de Noruega), el tercero, es que el Reino Unido se retire de la Ue sin ningún acuerdo y que sus relaciones comerciales con el bloque europeo se establezcan conforme al Acuerdo General sobre Aranceles Aduaneros y Comercio (Gatt), y el cuarto y último, es que se lleve a cabo un nuevo referéndum ante la opinión pública británica, quien decidirá el futuro del Reino Unido en la UE. Sin embargo, hasta el día de hoy el Reino Unido no ha ganado nada en relación con el Brexit. De manera contraria al sentimiento de la opinión pública británica, el Brexit ha generado más pérdidas que ganancias para el Reino Unido, tales como la dimisión de dos primeros ministros, la renuncia de una cantidad muy considerable de políticos británicos, así como la fuga de cuantiosas inversiones y empleos, debido a que un número muy considerable de empresas han escogido a otros países europeos debido a la incertidumbre que genera el Brexit para sus inversiones.

En relación con los fundamentos teóricos de esta investigación se puede aludir a que, desde la perspectiva de la teoría de los complejos de seguridad, el Reino Unido en muy pocas ocasiones compartió un sentido de "identidad colectiva" con el resto de los miembros de la 
UE, desde un perspectiva social, económica, política lo que finalmente propició el fenómeno inherente al Brexit, que ha llevado a la peor crisis que ha enfrentado la UE en toda su historia.

\section{REFERENCIAS}

Ayuso, A. (2019). Theresa May tres años sobre el volcán del Brexit. El Mundo. Recuperado desde https:// www.elmundo.es/internacional/2019/05/24/5ce 6e69821efa0d5488b46a1.html

Boix, L. (2012). Gran Bretaña-Escocia tensiones por referéndum independentista. Proceso. Recuperado desde http://www.proceso.com.mx/?p=295509

Brown, G. (2015). The truly patriotic British view on Europe? We must lead from within: The Guardian. Recuperado desde http://www.theguardian.com/ commentisfree/2015/mar/09/europe-gordonbrown-scotland-eu-business-britan

Brexit: el "dèjà vu" de 1975. Cuando los británicos votaron "sí" a Europa. El Mundo. Recuperado desde https://www.elmundo.es/la-aventura-dela-historia/2016/04/13/570cf8dbca4741ee64 8b4628.html

Britain and Europe Making the break. The Economist. Recuperado desde http://www.economist.com/ news/briefing/21567914-how-britain-could-fallout-european-union-and-what-it-would-meanmaking-break

Buzan, B. (2007). People, States and Fear: an agenda for international security in the post cold war era, Colchester: ECPR.

Buzan, B. y Waever, O. (2013). Regions and Powers: a guide to global security order, Cambridge: Cambridge University Press.
Buzan, B.; Waever, O. and Wilde, J. (1997). Security: a New Framework for Analysis, Boulder: Lynne Rienner Publishers.

Fresnesda, C. (2015). Tony Blair advierte que el referéndum de la ue traerá 'el caos al Reino Unido'. El Mundo. Recuperado desde http://www.elmundo. es/internacional/2015/04/07/5523c69f268e3e4 21e8b4572.html

Edward, S. (1998). The course of my life, Londres: Hodder $\&$ Stoughton Ltd.

Escocia dice 'no' a la independencia. El Mundo. Recuperado desde: tps://www.elmundo.es/internacional/ 2014/09/18/541b4b05ca4741c8058b4577.html Guimon, P. y Sahuquillo, M. (2016). "Brexit' vence e Reino Unido deixará a União Europeia. El País, 32. Recuperado el 24 de mayo de 2019 desde https://brasil.elpais.com/brasil/2016/06/24/internacional/1466741749_403437.html

Holmes, M. (1997). John Major and Europe: The Failure of a Policy 1990-7. Brugesgroup. Recuperado desde http://www.brugesgroup.com/eu/john-major-and-europe-the-failure-of-a-policy-1990-7. htm?xp=paper

Ibarra, L. (2019). Por qué los británicos desean abandonar la Unión Europea. Recuperado desde https://www.milenio.com/opinion/laura-ibarra/ columna-laura-ibarra/por-que-los-britanicosdesean-abandonar-la-union-europea

Lilico, A. (2015). David Cameron promises to withdraw Britain from the European Union. The Telegraph. Recuperado desde http://blogs.telegraph. co.uk/finance/andrewlilico/100028209/davidcameron-promises-to-withdraw-britain-fromthe-european-union-yes-i-mean-it/

8 razones por las que ganó el Brexit en el referendo sobre la permanencia de Reino Unido en la Unión Europea. El Mundo. Recuperado desde: 
https://www.bbc.com/mundo/noticias-internacional-36619175

Parzymies, S. (2013). Unia Europejska od Maastricht do Lizbony. Varsovia: Dialog.

Rodríguez, D (s.f.). Identidad cultural: características, elementos, formación, pérdida. Recuperado desde https://www.lifeder.com/identidad-cultural/

Sanhermeland, J. (2016). La historia de desamor entre el Reino Unido y la Unión Europea en seis pasos. Recuperado desde https://www.elespanol.com/ mundo/20160218/103239954_0.html
Tony Blair: el Brexit se puede parar. El Mundo. Recuperado desde: https://www.elmundo.es/internacion al/2016/11/24/5836fdab468aebfe5c8b4616.htm Wallerstein, I. (2015), Post Gran Bretaña: jacaso importa? La Jornada. Recuperado desde http://www. jornada.unam.mx/2015/05/24/index.php?secti on $=$ opinion $\&$ article $=024 \mathrm{a} 1 \mathrm{mun}$ 